\title{
Factors Predicting Nutrition and Physical Activity Behaviors Due to Cardiovascular Disease in Tehran University Students: Application of Health Belief Model
}

\author{
Fatemeh Rahmati-Najarkolaei ${ }^{1}$; Sedigheh Sadat Tavafian ${ }^{2, *}$; Mohammad Gholami Fesharaki ${ }^{3}$; \\ Mohammad Reza Jafari ${ }^{4}$ \\ ${ }_{2}^{1}$ Health Research Center, Baqiyatallah University of Medical Sciences, Tehran, IR Iran \\ ${ }^{2}$ Department of Health Educations, Faculty of Medical Sciences, Tarbiat Modaress University, Tehran, IR Iran \\ ${ }^{3}$ Biostatistics Department, Faculty of Medical Sciences, Tarbiat Modares University, Tehran, IR Iran \\ ${ }^{4}$ Department Of Psychology,College of Humanitiec saveh Science and Research Branch Islamic Azad University Saveh, IR Iran \\ ${ }^{*}$ Corresponding Author:Sedigheh Sadat Tavafian, Department of Health Educations, Faculty of Medical Sciences, Tarbiat Modaress University, Tehran, IR Iran. Tel:+98-2182884547, Fax: \\ +98-2182884555, E-mail: tavafian@modares.ac.ir
}

Received: March 11, 2014; Revised: May 7, 2014; Accepted: August 25, 2014

\begin{abstract}
Background: Disease preventing methods focus mostly on lifestyle factors such as physical activity, healthy diet and not smoking. Previous studies verified using theory and models to change unhealthy behaviors, so that health belief model(HBM) is a useful framework for describing the healthy nutrition behavior.

Objectives: This study aimed to predict factors related to unhealthy nutrition and inactive life in students of Tehran University, Tehran, Iran based on the Health Belief Model (HBM).

Patients and Methods: In this cross sectional study, proportional quota sampling from three different educational levels was conducted from October to December 2012. A self-administered validated instrument based on the Health Belief Model(HBM) with 69 items and four sections was used to collect data. In this study through using linear and logistic regression, the effect of body mass index, age, gender, marriage, self-efficacy, cues to action, knowledge, perceived severity, susceptibility, benefits and barriers on nutrition and physical activity behavior were assessed. SPSS version 18 was used to analyze data.

Results: Totally, 368 students including 318 female students (86.4\%) and 50 male students (13.6\%) with a mean age of 24.9 years $(\mathrm{SD}=4.55)$ took part in the study. Among all independent variables, gender $(\mathrm{P}<0.001)$, knowledge $(\mathrm{P}=0.023)$ and perceived barriers $(\mathrm{P}=0.004)$ predicted nutrition behavior. In case of physical activity, knowledge $(\mathrm{P}=0.011)$, perceived severity $(\mathrm{P}=0.009)$, perceived barriers $(\mathrm{P}=0.019)$ and self-efficacy $(\mathrm{P}=0.033)$ had significance association with physical activity behavior.

Conclusions: This study indicated that health belief model contrasts could predict the risky behavior of university students due to heart disease. However, more researches are needed to verify the predictors of high risky behaviors in students.
\end{abstract}

Keywords: Behavior; Heart Disease; Health Belief Model; Physical Activity

\section{Background}

Although cardiovascular disease has been decreased in developed countries, it is increasing in developing countries without noticeable public health responses (1). In Iran, like other developing countries, cardiovascular disease is the main reason of death and disability (2). It has been indicated that this disease causes about a half of all deaths (3). Furthermore, it was revealed that this increased rate has been due to increased major risk factors in Iran (4). The major risk factors like hypertension, hypercholesterolemia, smoking and diabetes are increased in this country (5). Recognition of patients with vascular disease and intervention with advice about life style, cigarette smoking, alcohol, nutrition and physical activity are among the preventing methods of cardiovascular disease (6). Disease preventing methods focus mostly on lifestyle factors such as physical activity, healthy diet and not smoking (7).

Previous studies verified applying theory and models to change unhealthy behaviors (8). Confederacy of international health education organizations (CNHEO) declared that theory and technology for the purpose of educational research should be used in methodology designing, performance and evaluation of health education programs. Theories and models are useful tools for health education experts (9).

Health Belief Model is one of the preventive models used for public health problem such as cardiovascular disease. This model was developed to explain lack of public participation in health screening and prevention programs in the 1950 s (10). In addition, this model is used

Copyright (C) 2015, Iranian Red Crescent Medical Journal. This is an open-access article distributed under the terms of the Creative Commons Attribution-NonCommercial 4.0 International License (http://creativecommons.org/licenses/by-nc/4.0/) which permits copy and redistribute the material just in noncommercial usages, provided the original work is properly cited. 
to examine patients' motivations for adopting a healthrelated behavior as well as assessing health-behavior interventions. It includes six key domains of perceived susceptibility, perceived severity, perceived benefits, perceived barriers, cues to action and self-efficacy (11). Selfefficacy domain refers to one's beliefs in one's capability to organize and execute the courses of action required to achieve given results (12).

In many evidences, self-efficacy has been associated with healthy nutrition (13) and physical activity behavior (14). In previous evidence, it was focused that higher levels of self-efficacy contributed to physical activity and lower dietary (15). Previous studies showed that health belief model is a useful framework for describing the healthy nutrition behavior (16-19). Moreover, this model has been used in risk reduction of cardiovascular disease in college students (20).

\section{Objectives}

Considering the importance of behavioral determinants of nutrition and physical activity behaviors due to cardiovascular disease, this study aimed to identify the important predictors of nutrition and physical activity in relation to cardiovascular disease in students of Tehran University.

\section{Patients and Methods}

\subsection{Participants}

This was a cross-sectional study performed on students of Tehran University from October to December 2012. A proportional quota sampling was used to select students studying in majors of humanity, basic sciences and technical-engineering in different grades of BS, MSC and PhD. Inclusion criteria were being student of Tehran University and aged between 18 and 55 years. Exclusion criteria were unwillingness to participate in the study and guest student from other universities. The sample size was calculated as 323 subjects considering $\alpha=5 \%$, statistical power of $90 \%, p=0.5, d=0.09$ and the following Equation:

$$
n=\frac{\left(Z_{\frac{\alpha}{2}}+Z_{\beta}\right)^{2} \mathrm{P}(1-\mathrm{P})}{d^{2}}
$$

Considering $10 \%$ attrition rate, we added 45 samples, so we totally considered 368 samples. In total, $36 \%$ were from engineering field, $11.3 \%$ basic sciences field and 52.7\% humanity field.

\subsection{Instruments}

A self-administrated questionnaire consisted of four sections was used to collect data. The first section was about demographic characteristics like age, gender, height, weight, level of education and information sources. The second part consisted of 16 questions regarding knowledge about causes, diagnosis and risk factors of cardiovascular disease, healthy diet and physical activity due to the disease prevention. The answering options of these questions were as "correct" with score of 1 , "incorrect" and "I do not know" with score of zero. In this scale, scores below 7 were considered as "weak", scores 8 - 11 as "average" and scores $\geq 12$ as "good". The third section of the questionnaire consisted of questions regarding Health Belief Model (HBM) constructs such as Perceived severity ( 4 items), Perceived benefits ( 5 items), perceived barriers (11 items), self-efficacy ( 4 items) and cues to action (3 questions) for healthy nutrition and physical activity behaviors due to cardiovascular disease prevention. These questions were answered through 5-point Likert options from totally agree to totally disagree ranged from 1 to 5 . In this regard, scores below 2.75 were considered as 'weak', 2.75 -3.74 as 'average' and more than 3.75 as 'high' score. The fourth section of the questionnaire was about nutrition and physical activity behavior ranged from 1 to 4 .

\subsection{Validity and Reliability}

Ten specialists, three cardiologists and others in health education field assessed the questionnaire content. In content validity, changing the format of questions and omitting irrelevant questions were performed. Afterward, mean Content Validity Index (CVI) and Content Validity Rate (CVR) of the questionnaire calculated as 0.83 and 0.77 , respectively.

Reliability of the scale was calculated through test-retest on 25 homogeneous students with two weeks interval. The correlation score was 0.73 for knowledge question, 0.71 for perceived susceptibility questions, 0.61 for perceived severity questions, 0.73 for self-efficacy questions, 0.65 for perceived benefits and barriers questions and 0.80 for cues to action questions. The Cronbach's alpha of knowledge questions were $0.66,0.62,0.51$, $0.54,0.68,0.50,0.70$ for perceived severity, perceived susceptibility, perceived benefits, perceived barriers, perceived self - efficacy and perceived cues to action, respectively.

\subsection{Data Analysis}

Data was analyzed using SPSS version 18 (SPSS Inc., Chicago, Ill, USA). Continuous variables were presented as mean \pm Standard Division (SD), whereas categorical data were presented as frequency and percentages. Kolmogorov-Simirnov test was used to check normal distribution of data. Also Linear Regression with enter method and Logistic regression method were used to study association between independent and response variables. $\mathrm{P}<$ 0.05 was considered as statistically significant. 
Rahmati Najarkolaei F et al.

\section{Results}

Totally, 368 subjects including 318 female students (86.4\%) and 50 male students (13.6\%) took part in the study. The mean age of participants was 24.9 years (SD = $4.55)$ and the mean weight was $59.58 \mathrm{~kg}(\mathrm{SD}=11.3)$. Table 1 shows other demographic characteristics.

The mean score of health belief model constructs and cardiovascular disease preventive behaviors are shown in Table 2.

To explore the predictor variables of nutrition and physical activity behaviors, the main independent variables such as knowledge and all health belief model constructs entered the regression model analysis. The results of this analysis are shown in Table 3. Accordingly, there was a positive association between knowledge and nutrition behavior $(\mathrm{P}=0.023)$ and a negative association between perceived barriers and this behavior $(\mathrm{P}=$ 0.004). Also in this model, male subjects showed lower mean nutrition behavior compared to female subjects $(\mathrm{P}<0.001)$.

Furthermore, predictor variables of physical activity behavior are shown in Table 4. According to this table, knowledge $(\mathrm{P}=0.011)$, perceived severity $(\mathrm{P}=0.009)$ and self-efficacy $(\mathrm{P}=0.033)$ showed positive associations with physical activity behavior, but perceived barriers had a negative association with this behavior $(\mathrm{P}=0.019)$.

\begin{tabular}{lc}
\hline \multicolumn{2}{l}{ Table 1. Demographic Characteristics of Participants ${ }^{\text {a }}$} \\
\hline Demographic Variable $(\mathbf{N}=\mathbf{3 6 8})$ & Values \\
\hline Gender & $50(13.6)$ \\
\hline Male & $318(86.4)$ \\
\hline Female & \\
\hline Employment status & $93(25.4)$ \\
\hline Employed & $275(74.6)$ \\
\hline Unemployed & \\
\hline Married status & $308(83.6)$ \\
\hline Single & $60(16.4)$ \\
\hline Married & $179(48.7)$ \\
\hline Academic degree & $156(42.5)$ \\
\hline Bachelors of science (BS) & $9(2.5)$ \\
\hline Master of Science (MSc) & $23(6.3)$ \\
\hline Medical Doctor (MD) & \\
\hline Philosophy of Doctor (PhD) & $264(71.7)$ \\
\hline Had Physical Activity & $104(28.3)$ \\
\hline Yes & \\
\hline No & $72(19.5)$ \\
\hline Positive Family history in cardio- \\
vascular disease
\end{tabular}

\begin{tabular}{lcc}
\hline Table 2. Scores of Health Belief Model on Cardiovascular Disease Preventive Behaviors ${ }^{\text {a }}$ & \\
\hline Variables & Scale Range & Values \\
\hline Knowledge & $0-16$ & $8.70 \pm 2.57$ \\
Perceived Severity & $4-20$ & $3.94 \pm 0.62$ \\
Perceived Susceptibility & $3-15$ & $3.11 \pm 0.74$ \\
Perceived Benefit & $5-25$ & $4.28 \pm 0.52$ \\
Perceived Barrier & $11-55$ & $3.36 \pm 0.54$ \\
Perceived Self efficacy & $4-20$ & $3.75 \pm 0.67$ \\
Perceived Cues to action & $3-15$ & $3.85 \pm 0.82$ \\
Nutrition preventive behavior & $23-92$ & $2.69 \pm 0.24$ \\
\hline
\end{tabular}

${ }^{\mathrm{a}}$ Data are presented as Mean \pm Standard Deviation.

\begin{tabular}{|c|c|c|c|c|c|}
\hline \multirow[t]{2}{*}{ Independent Variable } & \multirow[t]{2}{*}{ B } & \multirow[t]{2}{*}{ S.E. } & \multicolumn{2}{|c|}{ 95\% CI for OR } & \multirow[t]{2}{*}{ PValue } \\
\hline & & & Lower & Upper & \\
\hline Body mass index & 0.042 & 0.05 & -0.06 & 0.15 & 0.440 \\
\hline Age & 0.089 & 0.07 & -0.04 & 0.22 & 0.180 \\
\hline Gender (Male | Female) & -0.234 & 0.07 & -0.36 & -0.10 & $<0.001$ \\
\hline Marriage (Single | Married) & -0.090 & 0.06 & -0.21 & 0.03 & 0.155 \\
\hline Knowledge & 0.145 & 0.06 & 0.02 & 0.27 & 0.023 \\
\hline Perceived severity & 0.104 & 0.06 & -0.02 & 0.23 & 0.105 \\
\hline Perceived susceptibility & -0.095 & 0.06 & -0.20 & 0.01 & 0.087 \\
\hline Perceived benefits & -0.055 & 0.06 & -0.17 & 0.06 & 0.353 \\
\hline Perceived barriers & -0.182 & 0.06 & -0.30 & -0.06 & 0.004 \\
\hline Self-efficacy & -0.096 & 0.07 & -0.23 & 0.03 & 0.147 \\
\hline Cues to action & 0.101 & 0.06 & -0.02 & 0.23 & 0.112 \\
\hline
\end{tabular}

\footnotetext{
a Abbreviations: B, standardized beta; S.E., Standard Error; CI, Confidence Interval.
} 
Rahmati Najarkolaei F et al.

\begin{tabular}{|c|c|c|c|c|c|c|}
\hline \multirow[t]{2}{*}{ Independent Variable } & \multirow[t]{2}{*}{ B } & \multirow[t]{2}{*}{ S.E. } & \multirow[t]{2}{*}{ PValue } & \multirow[t]{2}{*}{ OR } & \multicolumn{2}{|c|}{ 95\% CI for OR } \\
\hline & & & & & Lower & Upper \\
\hline BMI & -0.043 & 0.055 & 0.433 & 0.958 & 0.860 & 1.067 \\
\hline Knowledge & 0.207 & 0.082 & 0.011 & 1.230 & 1.049 & 1.444 \\
\hline Perceived severity & 0.215 & 0.082 & 0.009 & 1.240 & 1.055 & 1.457 \\
\hline Perceived susceptibility & -0.109 & 0.074 & 0.141 & 0.897 & 0.775 & 1.037 \\
\hline Perceived benefits & -0.348 & 0.373 & 0.351 & 0.706 & 0.340 & 1.467 \\
\hline Perceived barriers & -0.919 & 0.392 & 0.019 & 0.399 & 0.185 & 0.859 \\
\hline Self - efficacy & 0.714 & 0.335 & 0.033 & 2.042 & 1.059 & 3.939 \\
\hline Cues to action & 0.559 & 0.291 & 0.055 & 1.749 & 0.989 & 3.093 \\
\hline Gender (Male|Female) & 0.356 & 0.690 & 0.606 & 1.428 & 0.370 & 5.516 \\
\hline Marriage (Single|Married) & -0.287 & 0.566 & 0.613 & 0.751 & 0.247 & 2.279 \\
\hline
\end{tabular}

a Abbreviations: B, beta; S.E., Standard Error; OR, Odds Ratio; CI, Confidence Interval.

\section{Discussion}

This study investigated how HBM constructs could predict nutrition and physical activity behaviors due to nutrition and physical activity in Tehran university students. Regarding nutrition behavior, this study found that gender, knowledge and perceived barrier could contribute to behavior. Accordingly, this study verified that female students had a better nutrition compared to male students. In consistent with this result, unhealthier nutrition behaviors in male students and lack of physical activity in female students were reported in previous study (21). Contrary to this finding, Bahreynian and coworkers found that healthy pattern of nutrition behavior in boys was better than girls, so that girls obtained higher Body Mass Index (BMI) than boys (22). Furthermore, previous evidence verified that determinants of food quality in students of Islands University were physical activity behavior, gender, age and the number of meals consumed per day (23). Another study demonstrated that there were differences between two genders regarding the receipt dietary fat (24). In another study, the dietary knowledge and behavior among female students were better than males $(25,26)$. Thus, it could be argued that in most studies, the important role of gender regarding nutrition behavior has been noticed. However, there are differences between studies to determine the role of gender in nutrition behavior. In the present study, most of target group were female students living in dormitories. Therefore, further studies with more male and female students should be performed.

In the present study, perceived barrier was predictor of nutrition behavior. In the study of Vassallo, it was revealed that perceived benefits and barriers could improve dietary regime (27). Furthermore, O'Connell demonstrated that perceived benefit is a strong predictor of dietary behavior among obese teenagers (28). However, in non-obese teenagers, the perceived susceptibility was the important factor predicting nutrition behavior. It seems that in healthy and unhealthy people, the role of perceived barriers is different so that in healthy people these variables are more effective.

The present study showed that knowledge has less effect on nutrition than the perceived barrier. However, previous evidence showed a significant relation between knowledge and food intake, so that knowledge has been an effective factor in defining food choice (29). Moreover, a previous evidence showed that consumers' nutrition knowledge was related to label use behavior (30).

However, some studies showed no significant associations between knowledge and dietary behavior (31). The present study showed that for physical activity behavior, perceived severity of cardiovascular disease could affect this behavior more than any other factors. Furthermore, in this study it was revealed that perceived barriers could predict physical activity. In consistent with this result, a previous study pointed out that physical activity levels of students were influenced by perceived barriers such as fear of strangers, bad weather and many school assignments (32). Therefore, motivation for walking should be affected by stressing on perceived benefits of physical activity such as positive health benefits, recreational benefits and a normal weight. In these motivational interviews, personal limitations such as lack of time, getting sunburn because of walking outdoors, non-supportive climate, traffic threat, crimes, etc. could be considered for students (33). The present study highlighted that selfefficacy could affect physical activity. Self-belief based factors could affect doing physical activity.

Garza and coworkers indicated that self-efficacy as a stronger predictor of the health belief model constructs could affect cardiovascular disease prevention behaviors (34).A previous study on patients with multiple sclerosis, self-efficacy and perceived benefits were the main determinants of physical activity (35). Furthermore, self-efficacy also predicted oral health behavior in other study (36). 
Parcel and coworkers indicated that self-efficacy plays a significant role in choosing the diets in students (37).

This study indicated that health belief model contrasts could predict the risky behavior of university students regarding cardiovascular disease. However, more researches are needed to verify other predictors of high risky behaviors in students.

\subsection{Limitations}

Although, this study had some strong points, there were some limitations such as self-reporting of questions responded by the participants. Furthermore, the study was performed through a cross sectional method in which the relations between the variables were not assessed. Besides, the instruments should be further analyzed regarding their validity and reliability.

\section{Acknowledgements}

We are grateful to Ms. Marjan Sheikhi for editing the manuscript.

\section{Authors' Contributions}

Fatemeh Rahmati Najarkolaei: designed the study and collected data. Sedigheh Sadat Tavafian: supervised the study. Mohammad Gholami Fesharaki: analyzed the data. Mohammad Reza Jafari: edited the paper.

\section{References}

1. Chang HS, Kim HJ, Nam CM, Lim SJ, Jang YH, Kim S, et al. The socioeconomic burden of coronary heart disease in Korea. J Prev Med Public Health. 2012;45(5):291-300.

2. Abbasi S, De Leon AP, Kassaian S, Karimi A, Sundin O, Soares J, et al. Gender differences in the risk of coronary artery disease in iran. Iran J Public Health. 2012;41(3):36-47.

3. Tofighi S, Ahmad Kiadaliri A, Sadeghifar J, Raadabadi M, Mamikhani J. Health-Related Quality of Life among Patients with Coronary Artery Disease: A Post-Treatment Follow-Up Study in Iran. Cardiol Res Pract. 2012;2012:973974.

4. Azizi F, Salehi P, Etemadi A, Zahedi-Asl S. Prevalence of metabolic syndrome in an urban population: Tehran Lipid and Glucose Study. Diabetes Res Clin Pract. 2003;61(1):29-37.

5. Kavousi M, Elias-Smale S, Rutten JH, Leening MJ, Vliegenthart R, Verwoert GC, et al. Evaluation of newer risk markers for coronary heart disease risk classification: a cohort study. Ann Intern Med. 2012;156(6):438-44.

6. Nelson MR, Tonkin A. Secondary prevention of CHD. Aust Fam Physician. 2005;34(6):433-40.

7. Cole JA, Smith SM, Hart N, Cupples ME. Systematic review of the effect of diet and exercise lifestyle interventions in the secondary prevention of coronary heart disease. Cardiol Res Pract. 2011;2011:232351.

8. Kaljee LM, Genberg BL, Minh TT, Tho LH, Thoa LT, Stanton B. Alcohol use and HIV risk behaviors among rural adolescents in Khanh Hoa Province Viet Nam. Health Educ Res. 2005;20(1):71-80.

9. DeBarr KA. A review of current health education theories. Californian J Health Promot. 2004;2(1):74-87.

10. Zhao J, Song F, Ren S, Wang Y, Wang L, Liu W, et al. Predictors of condom use behaviors based on the Health Belief Model (HBM) among female sex workers: a cross-sectional study in Hubei Province, China. PLoS One. 2012;7(11).

11. Coe AB, Gatewood SB, Moczygemba LR, Goode JV, Beckner JO. The use of the health belief model to assess predictors of intent to receive the novel (2009) H1N1 influenza vaccine. Inov Pharm. 2012;3(2):1-11.

12. Tsang SK, Hui EK, Law BC. Self-efficacy as a positive youth development construct: a conceptual review. ScientificWorldJournal. 2012;2012:452327.

13. Luszczynska A, Gibbons FX, Piko BF, Tekozel M. Self-regulatory cognitions, social comparison, and perceived peers' behaviors as predictors of nutrition and physical activity: A comparison among adolescents in Hungary, Poland, Turkey, and USA. Psychol Health. 2004;19(5):577-93.

14. Anderson ES, Winett RA, Wojcik JR, Williams DM. Social cognitive mediators of change in a group randomized nutrition and physical activity intervention: social support, self-efficacy, outcome expectations and self-regulation in the guide-to-health trial. $J$ Health Psychol. 2010;15(1):21-32.

15. Anderson-Bill ES, Winett RA, Wojcik JR. Social cognitive determinants of nutrition and physical activity among web-health users enrolling in an online intervention: the influence of social support, self-efficacy, outcome expectations, and self-regulation. $J$ Med Internet Res. 2011;13(1).

16. Hanson JA, Benedict JA. Use of the Health Belief Model to examine older adults' food-handling behaviors. J Nutr Educ Behav. 2002;34 Suppl 1:S25-30.

17. Dini Talatappeh H, Tavakoli HR, Rahmati Najarkolaei F, Dabbagh Moghadam A, Khoshdel A. Knowledge, Beliefs and Behavior of Food Consumption among Students of Military University: The Application of Health Belief Model (HBM). Iranian J Mil Med. 2012;14(3):192-9.

18. Abood DA, Black DR, Feral D. Nutrition education worksite intervention for university staff: application of the health belief model. J Nutr Educ Behav. 2003;35(5):260-7.

19. Sharifirad GR, Tol A, Mohebi S, Matlabi M, Shahnazi H, Shahsiah $M$. The effectiveness of nutrition education program based on health belief model compared with traditional training. J Educ Health Promot. 2013;2:15.

20. Sutliffe JT, Carnot MJ. Cardiovascular Risk Reduction among College Students. Fam Consum Sci Res J. 2011;39(3):256-66.

21. Dorner TE, Stronegger WJ, Hoffmann K, Stein KV, Niederkrotenthaler T. Socio-economic determinants of health behaviours across age groups: results of a cross-sectional survey. Wien Klin Wochenschr. 2013;125(9-10):261-9.

22. Bahreynian M, Paknahad Z, Maracy MR. Major dietary patterns and their associations with overweight and obesity among Iranian children. Int J Prev Med. 2013;4(4):448-58.

23. Moreno-Gomez C, Romaguera-Bosch D, Tauler-Riera P, BennasarVeny M, Pericas-Beltran J, Martinez-Andreu S, et al. Clustering of lifestyle factors in Spanish university students: the relationship between smoking, alcohol consumption, physical activity and diet quality. Public Health Nutr. 2012;15(11):2131-9.

24. Schafer RB, Keith PM, Schafer E. Predicting fat in diets of marital partners using the health belief model. J Behav Med. 1995;18(5):419-33.

25. Her ES. Eating Behavior, Nutrition knowledge, and Educational Needs of the Food and Nutrition of Elementary School Students in the Gyeungnam Province. Korean J Community Nutr. 2013;18(1):11-24.

26. Shah P, Misra A, Gupta N, Hazra DK, Gupta R, Seth P, et al. Improvement in nutrition-related knowledge and behaviour of urban Asian Indian school children: findings from the 'Medical education for children/Adolescents for Realistic prevention of obesity and diabetes and for healthy aGeing' ( MARG) intervention study. BrJ Nutr. 2010;104(3):427-36.

27. Vassallo M, Saba A, Arvola A, Dean M, Messina F, Winkelmann $\mathrm{M}$, et al. Willingness to use functional breads. Applying the Health Belief Model across four European countries. Appetite. 2009;52(2):452-60.

28. O'Connell JK, Price JH, Roberts SM, Jurs SG, McKinley R. Utilizing the health belief model to predict dieting and exercising behavior of obese and nonobese adolescents. Health Educ Q. 1985;12(4):343-51.

29. Wardle J, Parmenter K, Waller J. Nutrition knowledge and food intake. Appetite. 2000;34(3):269-75. 


\section{Rahmati Najarkolaei F et al.}

30. Drichoutis AC, Lazaridis P, Nayga RM. Nutrition knowledge and consumer use of nutritional food labels. Eur Rev Agricultural Econ. 2005;32(1):93-118.

31. Anand D, Puri S. Nutritional knowledge, attitude, and practices among HIV-positive individuals in India. J Health Popul Nutr. 2013;31(2):195-201.

32. Ar-Yuwat S, Clark MJ, Hunter A, James KS. Determinants of physical activity in primary school students using the health belief model. J Multidiscip Healthc. 2013;6:119-26.

33. Wan Omar WR, Patterson I, Pegg S. Using a Health Belief Model to investigate the walking behaviour of residents living in Kuala Lumpur, Malaysia. Ann Leisure Res. 2013;16(1):16-38.
34. Garza KB, Harris CV, Bolding MS. Examination of value of the future and health beliefs to explain dietary and physical activity behaviors. Res Social Adm Pharm. 2013;9(6):851-62.

35. Kasser SL, Kosma M. Health beliefs and physical activity behavior in adults with multiple sclerosis. Disabil Health J. 2012;5(4):261-8.

36. Buglar ME, White KM, Robinson NG. The role of self-efficacy in dental patients' brushing and flossing: testing an extended Health Belief Model. Patient Educ Couns. 2010;78(2):269-72.

37. Parcel GS, Edmundson E, Perry CL, Feldman HA, O'Hara-Tompkins $\mathrm{N}$, Nader PR, et al. Measurement of self-efficacy for diet-related behaviors among elementary school children. J Sch Health. 1995;65(1):23-7. 